\title{
A Note on the Optimal Punishment for Repeat Offenders
}

Winand Emons

$$
\text { 01-04 }
$$

December 2001

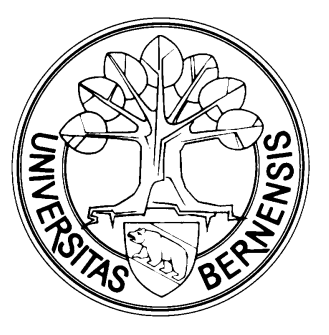

Universität Bern

Volkswirtschaftliches Institut

Gesellschaftstrasse 49

3012 Bern, Switzerland

Tel: $41(0) 316314506$

Web: www-vwi.unibe.ch 


\title{
A Note on the Optimal Punishment for Repeat Offenders
}

\author{
Winand Emons* \\ University of Bern and CEPR \\ December 2001
}

\begin{abstract}
Agents may commit a crime twice. The act is inefficient so that the agents are to be deterred. The agents are wealth constrained so that increasing the fine for the first offense means a reduction in the sanction for the second offense and vice versa. The agents may follow history dependent strategies. The government seeks to minimize the probability of apprehension. The optimal sanction scheme is decreasing rather than increasing in the number of offenses. Indeed, the sanction for the first offense equals the entire wealth while the sanction for the second offense is zero.

Keywords: crime and punishment, repeat offenders.

Journal of Economic Literature Classification Numbers: D82, K41, K42.

\footnotetext{
*Universität Bern, Volkswirtschaftliches Institut, Abteilung für Wirtschaftstheorie, Gesellschaftsstrasse 49, CH-3012 Bern, Switzerland, E-mail: winand.emons@vwi.unibe.ch, Homepage: www-vwi.unibe.ch/theory/emons03.htm. I thank Nuno Garoupa, Thomas Liebi, and Steve Shavell for helpful comments.
} 


\section{Introduction}

Most legal systems punish repeat offenders more severely for the same offense than non-repeat offenders. Second-time offenders, for example, receive more severe punishment than first-time offenders. Penalty escalation characterizes traditional crimes such as theft and murder, but also violations of environmental and labor regulations, tax evasion, etc. This principle of escalating sanctions based on offense history is so widely accepted that it is embedded in many penal codes and sentencing guidelines.

For the rather well developed law and economics literature on optimal law enforcement escalating sanction schemes are still a puzzle. ${ }^{1}$ This literature looks for an efficiency-based rationale for such a practice. Does a sanction scheme that minimizes enforcement costs indeed have the property of sanctions increasing with offense history? So far the results have been mixed. At the very best the literature, which we describe at the end of this introduction, has shown that under rather special circumstances escalating penalty schemes may be optimal.

The purpose of this note is to add to this puzzle. We consider agents who may commit a crime twice. The act is inefficient so that the agents are to be deterred. The agents are wealth constrained so that increasing the fine for the first offense means a reduction in the possible sanction for the second offense and vice versa. The agents may follow history dependent strategies, i.e., commit the crime a second time if and only if they were (were not) apprehended the first time. The government seeks to minimize the probability of apprehension.

Our basic result is that the optimal sanction scheme is decreasing rather than increasing in the number of offenses. Indeed, in our framework it is optimal to set the sanction for the first offense equal to the entire wealth of the agents while the sanction for the second offense equals zero. The key intuition is as follows: A money penalty imposed for the second offense reduces the amount a person can pay for the first offense, since the wealth available to pay penalties is assumed to be fixed over the two periods. For that reason, a higher probability event - namely, a first offense that is detected - will be more effective use of the scarce money penalty resource than a lower probability event - namely, a second detected offense.

Why is the probability of detection lower for the second rather than for the first crime? An agent faces the possibility of being sanctioned for the

\footnotetext{
${ }^{1}$ See, e.g., Garoupa (1997) or Polinsky and Shavell (2000) for surveys of this literature.
} 
second crime if and only if she has already been sanctioned for the first time. Moreover, suppose the first act went undetected and the agent commits the second crime; then there is the possibility that she is apprehended for the second crime for which she is charged, however, the first-time sanction since she has no criminal record. Accordingly, whatever strategy the agent opts for, she is more likely to pay the sanction for the first rather than for the second crime. Shifting scarce wealth from the second to the first sanction, therefore, increases deterrence.

Let us now discuss the related literature. In Rubinstein (1979) even if an agent abides by the law, she may commit the act accidentally. The government wishes to punish deliberate offenses but not accidental ones. Rubinstein shows that in the infinitely repeated game an equilibrium exists where the government does not punish agents with a "reasonable" criminal record and the agents refrain from deliberate offenses.

Rubinstein (1980) considers a setup where an agent can commit two crimes. A high penalty for the second crime is exogenously given. The sanction for the first crime may be lower than the sanction for the second crime. Rubinstein shows that for any set of parameters there exists a utility function such that deterrence is higher if the sanction for the first crime is lower than the sanction for the second crime. Rubinstein does not allow for the second sanction to be lower than the first one.

Landsberger and Meilijson (1982) develop a dynamic model with repeat offenses. Their concern is how prior offenses should affect the probability of detection rather than the level of punishments.

In Polinsky and Rubinfeld (1991) agents receive an acceptable as well as an illicit gain from the criminal activity. The government cannot observe the illicit gains. Repeat offenses are, however, a signal of a high illicit gain. For certain parameter values of the model it may be optimal to punish repeat offenders more severely.

In Burnovski and Safra (1994) agents decide ex ante on the optimal number of crimes. They show that if the probability of detection is sufficiently small, reducing the sanction on subsequent crimes while increasing the penalty on previous crimes decreases the overall criminal activity. This paper is similar in spirit to ours. The main differences are: In their framework agents cannot choose strategies that depend on history, in our setup they can. Moreover, we derive the optimal policy that minimizes enforcement costs.

In Polinsky and Shavell (1998) agents live for two periods and can commit 
a crime twice. The government observes the agent's age and her criminal record. They show that the following policy may be optimal: Young firsttime offenders and old second-time offenders are penalized with the maximum sanction. Old first-time offenders may be treated leniently. Accordingly, this result does not say that repeat offenders are punished more severely; old first-time offenders may be punished less severely than old repeat- and young first-time offenders.

Chu, Hu, and Huang (2000) consider like Rubinstein (1979) a legal system that may also convict innocent offenders. The government takes the possibility of erroneous conviction as a social cost into account. The optimal penalty scheme punishes repeat offenders (slightly) more than first-time offenders. Reducing the penalty for first-time and increasing it slightly for repeat offenders has no effect on deterrence. The cost of erroneous convictions is, however, reduced because the probability of repeated erroneous conviction is lower than for first-time mistakes.

Dana (2001) argues that contrary to the assumptions in the literature, probabilities of detection increase for repeat offenders. As a result, the optimal deterrence model dictates declining, rather than escalating, penalties for repeat offenders. Taking the salience and optimism biases from behavioral economics into account makes the case for declining penalties even stronger.

In the next section we describe the model and derive our basic result. Section 3 concludes.

\section{The Model}

Consider a set of individuals who live for two periods. In each period the agents can engage in an illegal activity, such as false parking, polluting the environment, or evading taxes. If an agent commits the act in either period, she receives a monetary benefit $b>0$. Yet the act causes a monetary harm $h>0$ to society. Let $h>b$ so that the act is not socially desirable. The individuals are to be deterred from the activity. ${ }^{2}$

To do so the government chooses sanctions. The government cannot tell whether an agent is in the first or second period of her life. The government only observes whether the crime is the first or the second one. Accordingly, the government uses fines $s_{1}, s_{2} \geq 0$ where $s_{1}$ applies to first-time and $s_{2}$

\footnotetext{
${ }^{2}$ We assume that the benefits and the harms are the same for both crimes. If, say, the benefit of the second crime were much higher than the benefit of the first one, this might provide a rationale for escalating penalties.
} 
to second-time offenders. Moreover, the government chooses a probability of apprehension $p$. This probability is the same for first- and second-time offenses. ${ }^{3}$ Since apprehension is costly, the government wishes to minimize $p$.

Individuals are risk neutral and maximize expected income. They have initial wealth $W>0$. Think of $W$ as the value of the privately owned house or assets with a long maturity. The agents hold on to their wealth over both periods unless government interferes with sanctions. Any additional income they receive in both periods, be it through legal or illegal activities, is consumed immediately. Accordingly, all the government can confiscate is $W$. If the fine exceeds the agent's wealth, she goes bankrupt and the government seizes the remaining assets. This implies that the fines $s_{1}$ and $s_{2}$ have to satisfy the "budget constraint" $s_{1}+s_{2}=W .4$

To save on notation let the interest rate be zero. An agent can choose between the following strategies:

- She can choose not to commit the act at all. We call this strategy $(0,0)$ which gives rise to utility $U(0,0)=W$. This is the strategy we wish to implement.

- She can choose to commit the act in period 1 and not in period 2 . Call this strategy $(1,0)$; here we have $U(1,0)=W+b-p s_{1}$. The act generates benefit $b$; with probability $p$ the agent is apprehended and pays the sanction $s_{1}$.

- The agent can opt to commit the crime in period 2 but not in period 1. Call this strategy $(0,1)$ generating utility $U(0,1)=W+b-p s_{1}$. With strategy $(0,1)$ the agent has the same utility as with strategy $(1,0)$ because the government observes only one offense.

- Moreover, the agent can commit the act in both periods which we denote by $(1,1)$ and $\left.U(1,1)=W+b-p s_{1}+b-p\left((1-p) s_{1}+p s_{2}\right)\right)$.

\footnotetext{
${ }^{3}$ We thus rule out the case where agents with a criminal record are more closely monitored than agents without a record. See Landsberger and Meilijson (1982) for an analysis of optimal detection probabilities.

${ }^{4}$ This assumption distinguishes our approach from Polinsky and Shavell (1998) who work with a maximum per period sanction $s_{m}$. Accordingly, they may set $s_{1}=s_{2}=s_{m}$, which is typically the optimal enforcement scheme. In their framework $s_{m}$ is like a per period income which cannot be transferred into the next period. Burnovski and Safra (1994) use the same budget constraint as we do.
} 
The second crime is detected with probability $p$. With probability $p$ the agent has a criminal record in the second period and thus is fined $s_{2}$; with probability $(1-p)$ she has no record and pays $s_{1}$ if apprehended.

- Finally, the agent can choose two history dependent strategies. ${ }^{5}$ First, she commits the act in period 1. If she is not apprehended, she also commits the act in period 2; however, if she is apprehended in period 1 , she does not commit the act in period 2. Call this strategy (1, (1) no record;0|otherwise $))$ with $U(1,(1 \mid$ no record; $0 \mid$ otherwise $))=W+b-$ $p s_{1}+(1-p)\left(b-p s_{1}\right)$. Since the agent stops her criminal activities if she is apprehended once, she is never sanctioned with $s_{2}$.

- Second, she commits the act in period 1. If she is not apprehended, she does not commit the act in period 2; however, if she is apprehended in period 1 , she commits the act in period 2. Call this strategy $(1,(0 \mid$ no record; $1 \mid$ otherwise $))$ with $U(1,(0 \mid$ no record; 1 otherwise $))=W+b-$ $p s_{1}+p\left(b-p s_{2}\right)$. It turns out that this strategy defines the binding incentive constraint for the optimal sanctions.

Let us now derive sanctions that give the agents proper incentives not to engage in the activity in either period. We assume that agents have enough wealth so that deterrence is always possible, i.e., $2 b<W$. The agent does not follow strategy $(1,0)$, if $U(1,0) \leq U(0,0)$, she does not follow strategy $(0,1)$, if $U(0,1) \leq U(0,0)$, etc. Straightforward computations confirm that the agent does not engage in strategies $(1,0),(0,1)$, and $(1,(1 \mid$ no record; $0 \mid$ otherwise $))$, if

$$
s_{1} \geq b / p
$$

she does not pick strategy $(1,1)$, if

$$
s_{2} \geq\left(2 b / p^{2}\right)-s_{1}((2 / p)-1)
$$

and she does not pick strategy $(1,(0 \mid$ no record; $1 \mid$ otherwise $))$, if

$$
s_{2} \geq\left(b(1+p) / p^{2}\right)-s_{1} / p \text {. }
$$

insert Figure 1 around here

\footnotetext{
${ }^{5}$ These history dependent strategies distinguish our paper from Burnovski and Safra (1994) where individuals decide ex ante simply on the number of crimes.
} 
Accordingly, with all sanction schemes $\left(s_{1}, s_{2}\right)$ to the right of the bold line in Figure 1, the agent has proper incentives and commits no crime. For example, the scheme $\hat{s}_{1}=\hat{s}_{2}=b / p$ induces no crimes. Note that we can lower $\hat{s}_{2}$ by 1 while increasing $\hat{s}_{1}$ by 1 and stay within the set of incentive compatible schemes, because $1 / p \geq 1$. This is a generalized version of the Burnovski and Safra (1994) result, because we also allow for history dependent strategies which they don't.

Let us next tackle the task of minimizing the enforcement costs, as given by $p$, while providing incentives not to commit any crime. We will minimize $p$ taking the incentive constraint (3) into account. Then we show that the optimal $p^{*}$ also satisfies the incentive constraints (1) and (2).

Obviously, Becker's (1968) maximum fine result applies here, meaning that in order to minimize $p$ the government will use the agent's entire wealth for sanctions. ${ }^{6}$ Accordingly, plugging the budget constraint $s_{1}+s_{2}=W$ into (3) and differentiating the equality yields $d p / d s_{1}=\left(p-p^{2}\right) /\left(b-s_{1}-2 p(W-\right.$ $\left.\left.s_{1}\right)\right)<0$ for $b<s_{1} \leq W$. Consequently, $s_{1}^{*}=W, s_{2}^{*}=0$, and $p^{*}=b /(W-b)$. Since $b / p<2 b / p(1-p)<b(1+p) / p \forall p \in(0,1)$, the incentive constraints (1) and (2) are also satisfied.

We thus find that the optimal sanction scheme sets $s_{1}^{*}=W$ and $s_{2}^{*}=0$. First time offenders are punished with the maximal possible sanction while second time offenders are not punished at all. The sanction $s_{1}$ is high enough that it not only deters first-time offenses but also second-time offenses even though they come for free.

The intuition for this result follows immediately from the incentive constraint (3). The agent pays the sanction $s_{1}$ with probability $p$ and the sanction $s_{2}$ only with probability $p^{2}$. To put it differently: The agent is charged $s_{2}$ with probability $p$ if and only if she has paid already $s_{1}$. Since paying the fine $s_{1}$ is more likely than paying $s_{2}$, shifting resources from $s_{2}$ to $s_{1}$ increases deterrence for given $p$. Consequently, $p$ is minimized by putting all the scarce resources into $s_{1}$.

It is perhaps somewhat surprising that the strategy $(1,(0 \mid$ no record; $1 \mid$ otherwise)) and not the strategy (1,(1|no record;0|otherwise)) defines the binding incentive constraint in the optimal penalty structure. Given that the optimal penalties are declining, an agent who was not apprehended for the first crime has a strong incentive not to commit the act a second time: if she is apprehended she pays the high sanction $s_{1}$. If the agent was, however, ap-

\footnotetext{
${ }^{6}$ If $s_{1}+s_{2}<W$, sanctions can be raised and $p$ lowered so as to keep deterrence constant.
} 
prehended for the first crime, the second crime comes for free. The sanction $s_{1}$ has to be high enough so that she doesn't commit the first crime in the first place.

\section{Conclusions}

The purpose of this note is to help understand the difficulties the law and economics literature has in explaining escalating penalties. If a higher sanction for the second crime means a lower sanction for the first crime and vice versa, cost minimizing deterrence is decreasing, rather than increasing, in the number of offenses. ${ }^{7}$ Since an agent can only be a repeat offender if she has been a first-time offender, there is no second offense if we completely deter the first one. This effect seems to be quite robust and should also apply to non-monetary sanctions. Accordingly, if one wants to give a rationale for the widely prevailing escalating penalties, one has to go beyond the simple deterrence model à la Becker. ${ }^{8}$ The rationale for escalating sanctions has to be stronger than the effect identified in this note.

We have looked at the case where the government wants complete deterrence. If we take a framework with non-identical agents where some underdeterrence is efficient, with our sanction scheme those who are under-deterred will always be repeat offenders because the second crime is free. Yet our result still holds if some individuals should commit the crime twice because their benefits are high and the rest should commit no crime at all because their benefits are low. If we wish, however, to implement more complicated crime structures, the optimal sanction scheme may be different from ours.

\footnotetext{
${ }^{7}$ Similar results hold in repeated moral hazard situations. For example, if agents decide strategically over time on how carefully to treat a consumer durable, optimal incentive compatible warranties tend to increase, rather than decrease, with the product's age. See Emons (1989).

${ }^{8}$ Perhaps one has to call upon the notions of fairness, moral, and justice to explain increasing sanctions.
} 


\section{References}

Becker, G.: Crime and Punishment: An Economic Approach, Journal of Political Economy, 76 (1968), 169-217.

Burnovski, M. And Z. SAFra: Deterrence Effects of Sequential Punishment Policies: Should Repeat Offenders be more Severely Punished, International Review of Law and Economics, 14 (1994), 341-350.

Chu, C. Y. Cyrus, Sheng-cheng Hu, and Ting-yuan Huang: Punishing Repeat Offenders more Severely, International Review of Law and Economics, 20 (2000), 127-140.

Dana, D. A.: Rethinking the Puzzle of Escalating Penalties for Repeat Offenders, Yale Law Journal, 110 (2001), 733-783.

Emons, W.: On the Limitation of Warranty Duration, Journal of Industrial Economics, 37 (1989), 287-302.

GaroupA, N.: The Theory of Optimal Law Enforcement, Journal of Economic Surveys, 11 (1997), 267-295.

Landsberger, M. And I. Meilijson: Incentive Generating State Dependent Penalty System, The Case of Income Tax Evasion, Journal of Public Economics 19 (1982), 333-352.

Polinsky, M. And S. Shavell: The Economic Theory of Public Enforcement of Law, Journal of Economic Literature, 38 (2000), 45-76.

Polinsky, M. and S. Shavell: On Offense History and the Theory of Deterrence, International Review of Law and Economics, 18 (1998), 305-324.

Polinsky, M. And D. Rubinfeld: A Model of Fines for Repeat Offenders, Journal of Public Economics 46 (1991), 291-306.

Rubinstein, A.: An Optimal Conviction Policy for Offenses that May Have Been Committed by Accident, in: Applied Game Theory, S. Brams, A. Schotter, and G. Schwödiauer (Eds.) Würzburg, Physica-Verlag, 1979, 406-413.

Rubinstein, A.: On an Anomaly of the Deterrent Effect of Punishment, Economics Letters, 6 (1980), 89-94. 


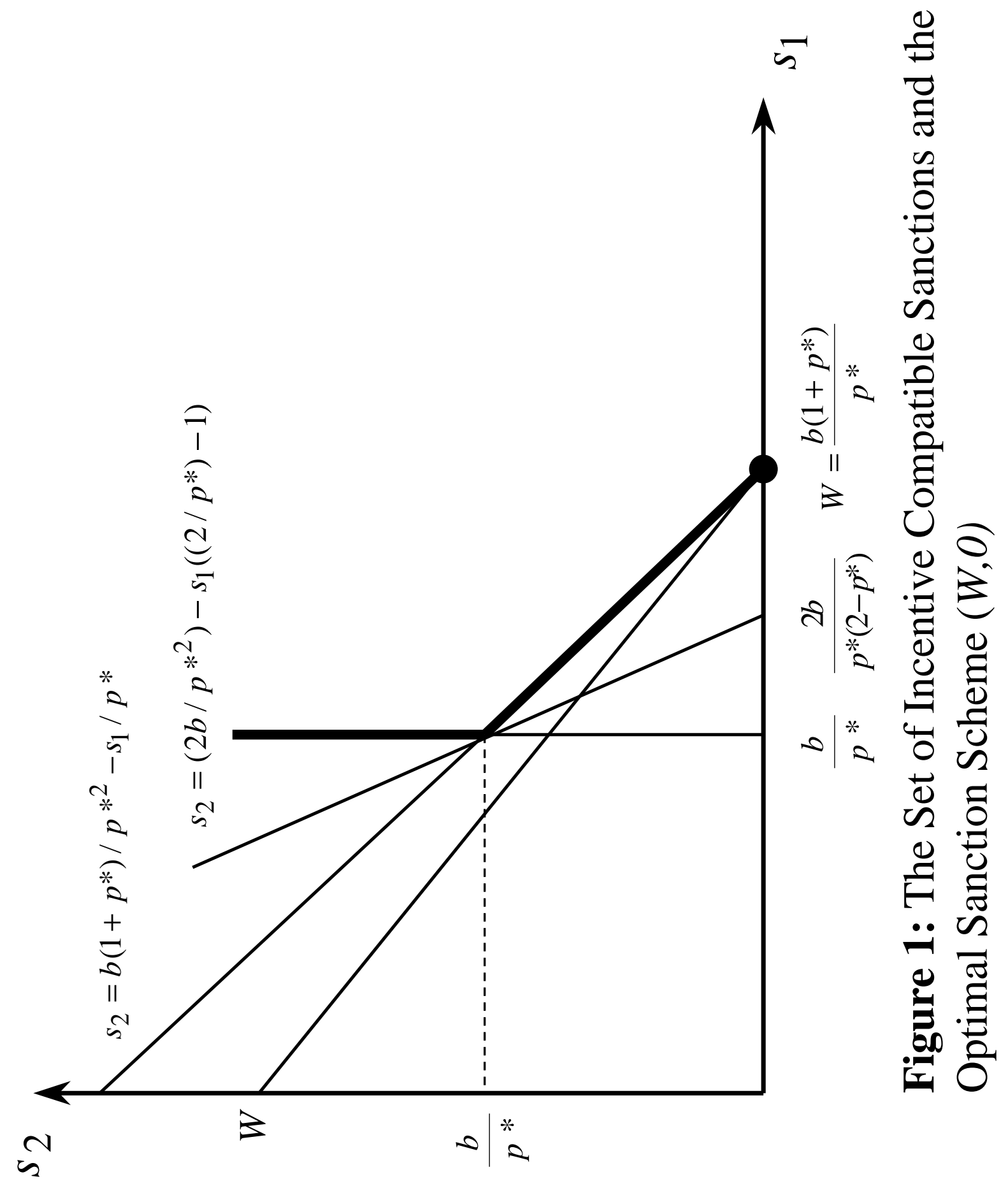

